\title{
Distinguishing the Explicit Power Motives
}

\section{Relations With Dark Personality Traits, Work Behavior, and Leadership Styles}

\author{
Kaspar Schattke and Ariane S. Marion-Jetten \\ Department of Psychology, Université du Québec à Montréal, Canada
}

\begin{abstract}
Power is an important motivator at work, particularly for leaders. However, power also relates to dark personality traits, which negatively affect employees and organizations. Therefore, we argue that a high explicit power motive is a double-edged sword depending on whether people desire power for dominance, prestige, or leadership. We explored these research questions in a cross-sectional $(\mathrm{N}=151$ employees) and a prospective study ( $N=371$ leaders). Both studies revealed that dominance is most strongly related to Machiavellianism and moderately to narcissism and psychopathy. Prestige related strongly to narcissism and weakly to Machiavellianism, while leadership only weakly related to narcissism. Dominance best predicted counterproductive work behavior (CWB), while leadership best-predicted organizational citizenship behavior (OCB). In addition, Study 2 showed that transformational and, to a lesser extent, transactional leadership styles mediated the relations between the three power motives with OCB and CWB, respectively. Thus, promoting transformational leadership might be a fruitful way of channeling leaders' power motives into pro-social actions.
\end{abstract}

Keywords: explicit power motive, dark triad, organizational citizenship behavior (OCB), counterproductive work behavior (CWB), transformational leadership

What motivates leaders? Is it having power over others? And if so, is this good or bad? McClelland (1975) defined the power motive as the desire to feel strong and impactful. People can achieve this feeling by influencing or arousing strong emotions in others or maintaining reputation and prestige, which can be for the better or the worse (Winter, 2006). Later, McClelland and colleagues (1989) distinguished implicit from explicit motives. Implicit motives are unconscious and usually predict performance over longer periods. Explicit motives are conscious, self-attributed motives and predict decisions. The implicit power motive is an important predictor of leadership emergence (McClelland \& Boyatzis, 1982), while the explicit power motive has been associated with positive leadership perceptions (e.g., Lord et al., 1986). Notably, the explicit power motive is also associated with dark personality traits (Jonason \& Ferrell, 2016), which, in turn, relate to counterproductive work behavior (CWB; O’Boyle et al., 2012). In leaders, these dark behaviors negatively affect employees and organizations (Schyns \& Schilling, 2013).

Therefore, a high explicit power motive at work might be a double-edged sword: while it relates to people being seen as good leaders, it also overlaps with dark personality traits such as narcissism, Machiavellianism, and psychopathy (Jonason \& Ferrell, 2016). Moreover, a strong desire for power and dominance seem to play a prominent role in dark leadership (Furtner et al., 2017). Yet, a recent study suggested that the heterogeneous conceptualization of the explicit power motive had been the reason for previous inconsistent results (Suessenbach et al., 2019). These authors suggested dividing the explicit power motive into a desire for dominance, prestige, and leadership and provided reliable and valid scales to measure them. Therefore, we posit that the reasons why people desire power will determine how the explicit power motive relates to dark personality traits and organizational behavior. Since the explicit power motive is an important predictor for leadership and organizational behavior, it appears theoretically and practically useful to explore the differential relations of the motives for dominance, prestige, and leadership (1) with the dark triad - narcissism, Machiavellianism, and psychopathy - (2) with positive and negative work behavior as well as (3) with leadership styles. To our knowledge, this is the first research investigating these questions.

\section{The Explicit Power Motive}

The power motive is a personality disposition that directs, energizes, and selects behavior toward having an impact on others, influencing people's thoughts, emotions, or 
behavior, as well as attaining prestige and reputation (McClelland, 1975). While McClelland (1975) initially assessed the power motive exclusively with projective measures, McClelland and colleagues (1989) stated that motives could also be assessed using self-report measures. However, such an "explicit" motive would predict different outcomes, such as conscious decisions and other questionnaire measures. Researchers have been operationalizing the explicit power motive as values (Schwartz, 1994), selfdescriptions (Jackson, 1967), goals (Pöhlmann \& Brunstein, 1997), or a mixture of those (Schönbrodt \& Gerstenberg, 2012). On the one hand, the latter approach showed a high measurement precision, and the explicit power motive predicted, for example, egoistic behavior in the dictator game (Schönbrodt \& Gerstenberg, 2012). On the other hand, the explicit power motive is conceptually heterogeneous including dominating others, gaining prestige, and directing and helping others. Thus, Suessenbach and colleagues (2019) concluded that it was no wonder that relations between the explicit power motive and outcome variables could be highly dependent on the specific scale and have recently introduced a taxonomy of different reasons for desiring power. They derived their taxonomy from an evolutionary and social hierarchy approach to power, which assumes that people on the top of a social hierarchy can acquire their power from three qualitatively different sources: dominance, prestige, and leadership.

Dominance is based on forcing others to obey one's will. In its simplest form, one obtains it through superior physical strength. Less costly strategies include other forms of "aggression, dominant body postures, glares, vocal pitch, verbal threats, emotional blackmailing or deception" (Suessenbach et al., 2019, p. 8). Dominance seems to be mainly based on coercive power and, to some extent, on reward power according to French and Raven's (1959) well-established taxonomy for the bases of power. Suessenbach and colleagues (2019) report that the scale strongly relates to verbal aggression and moderately to anger, agreeableness (negatively), and social dominance orientation wanting one's in-group to dominate and to be superior (Pratto et al., 1994). It also predicted retaliatory behavior in the dictator game (Suessenbach et al., 2019). In sum, people with a high motive for dominance force others into deference by intimidation and coercion.

Prestige is based on seeking admiration and respect. To establish ones' position on top of the social hierarchy, one would try to gain valued but difficult to obtain knowledge and skills. Consequently, others would need to woo the person possessing the required knowledge or skills to benefit from them, which then bestows status and prestige on that person (Suessenbach et al., 2019). Prestige seems to be based on expert and, to some extent, on referent power (French \& Raven, 1959). The scale strongly relates to the explicit achievement, affiliation, and fear of losing reputation motives. It is moderately related to helping behavior, such as pro-social donating and claiming moral standards (Suessenbach et al., 2019). In sum, people with a high motive for prestige seek voluntary deference through knowledge and skills.

Leadership is based on taking responsibility for one's group and directing its members' efforts toward a common goal. The leading position in the hierarchy is neither achieved by force nor by voluntary deference but through a dynamic process of claiming and granting power. In situations where the group needs a capable coordinator to achieve important goals, people who desire directing others will claim the leadership role. Thereupon, the group will grant this role to one of the aspirants. This is what French and Raven (1959) refer to as legitimate power. The scale strongly relates to extraversion, explicit achievement, and affiliation motives, and moderately to emotional stability, conscientiousness, and helping behavior. It further predicted higher employment ranks in different professions (Suessenbach et al., 2019). In sum, people with a high motive for leadership desire to lead others toward important group goals.

Given the previously observed relations of dark personality traits with the mono-dimensional explicit power motive (Jonason \& Ferrell, 2016), we aimed at exploring the specific relations of dominance, prestige, and leadership with the three dark personality traits outlined in the following section.

\section{Dark Personality Traits}

Paulhus and Williams (2002) conceptualized narcissism, Machiavellianism, and psychopathy as omnibus traits reflecting subclinical counterparts of the personality disorders. Previous research has studied the dark traits as separate factors as well as one combined "dark triad," predicting a plethora of negative outcomes in the workplace (LeBreton et al., 2018), including destructive leadership and CWB (Furtner et al., 2017; O'Boyle et al., 2012). Narcissism, Machiavellianism, and psychopathy all entail "a socially malevolent character with behavior tendencies toward self-promotion, emotional coldness, duplicity, and aggressiveness" (Paulhus \& Williams, 2002, p. 557). Like the dominance, prestige, and leadership motives, the dark triad is best measured as separate factors (Furtner et al., 2017), for example, with the concise "Dirty Dozen" measure (Jonason \& Webster, 2010).

Narcissism is a personality trait that encompasses a person's sense of grandiosity, entitlement, superiority, and dominance (Raskin \& Hall, 1979). Narcissists tend to selfenhance, be selfish, and put others down (Jones \& Paulhus, 2011). Narcissism is a multifaceted construct, and scholars 
have not yet agreed on all underlying components, yet Crowe and colleagues (2019) conclude that most scholars accept distinguishing grandiose (general personality trait) from vulnerable (pathological) narcissism. Accordingly, grandiose narcissism relates to narcissistic leadership (Rosenthal \& Pittinsky, 2006) and vulnerable narcissism to depression (Erkoreka \& Navarro, 2017). However, Crowe and colleagues (2019) suggested the three factors Agentic Extraversion, Narcissistic Neuroticism, and Self-Centered Antagonism would consolidate the convergent and divergent aspects of grandiose and vulnerable narcissism. Foster and colleagues (2015) further differentiated grandiose narcissism suggesting a seven-factor solution, whereas Back and colleagues (2013) had suggested a more parsimonious two-dimensional process model through which narcissists try to maintain their grandiose self: self-promotion (Narcissistic Admiration) and self-defense (Narcissistic Rivalry). Suessenbach and colleagues (2019) showed that dominance strongly correlated with narcissistic admiration and rivalry. While prestige and leadership also correlated strongly with Narcissistic Admiration, their correlations with Narcissistic Rivalry were considerably smaller. Unfortunately, no data are available for the relations of dominance, prestige, and leadership with Machiavellianism and psychopathy.

Machiavellianism entails a manipulative personality, which can be reflected by the extent to which people endorse statements taken from Machiavelli's writings (Christie \& Geis, 1970). People high in Machiavellianism lack empathy, tend to seek dominance and are ready to lie and exploit others to attain their goals (Jones \& Paulhus, 2011), which often include money, power, and status. However, unlike narcissists, Machiavellians do not look for admiration per se: self-promotion and self-aggrandization serve other goals (Furtner et al., 2017). One can map Machiavellianism on the five-factor model of personality, resulting in a profile of 13 facets that include high Conscientiousness and low Agreeableness. A short version of this scale with the three higher-order factors Antagonism (selfish and manipulative), Agency (assertive and feeling invulnerable), and Planfulness (deliberate and orderly) can distinguish Machiavellianism well from psychopathy (Du et al., 2021).

Psychopathy combines impulsivity and thrill-seeking with low empathy, callousness, and interpersonal manipulation (Paulhus \& Williams, 2002). Psychopaths are aggressive, lack remorse, and will seek immediate gratification. Patrick and colleagues (2009) suggested a triarchic conceptualization of psychopathy that entails the three distinct constructs of Disinhibition (problem with impulse control), Boldness (socially dominant and venturesome), and Meanness (aggressive and no regard for others). Notably, Disinhibition distinguished people high on psychopathy from the planned and controlled Machiavellians (Du et al., 2021).
Given the various and often heterogeneous approaches in subdividing narcissism, Machiavellianism, and psychopathy (cf. LeBreton et al., 2018), this research uses Paulhus and Williams' approach, conceptualizing narcissism, Machiavellianism, and psychopathy as subclinical and "overlapping but distinct constructs" (2002, p. 556). Using this conceptualization, all dark triad traits show conceptual overlap with the power motive for seeking dominance (forcing others into deference), particularly Machiavellianism and psychopathy. Therefore, we posit

Hypothesis 1a: Dominance correlates positively with narcissism, Machiavellianism, and psychopathy with stronger correlations for Machiavellianism and psychopathy.

Prestige (deference through knowledge and skills) seems to be conceptually the closest related to narcissism, but people high in Machiavellianism might use status as a means for achieving their goals. Therefore, we posit

Hypothesis 1b: Prestige correlates positively with narcissism and less strongly with Machiavellianism.

Leadership (desire to lead) seems to share the least conceptual overlap with the dark triad variables. However, given the sense of grandiosity, entitlement, and superiority characterizing narcissism, we see some overlap, for example, in the form of narcissistic leadership (Rosenthal \& Pittinsky, 2006). Moreover, Ackerman and colleagues (2011) proposed a leadership/authority factor in narcissism that conceptually overlaps with the leadership motive. Therefore, we posit

Hypothesis 1c: Leadership positively correlates with narcissism.

\section{Positive and Negative Work Behavior}

Besides testing the empirical associations of the three explicit power motives with the three dark personality traits, we also explore their links with positive and negative work behavior. Organizational citizenship behavior (OCB) entails going beyond duty and involves extra-role behavior; it supports task performance by enhancing the organizational environment (Organ, 1997). OCB relates to outcomes such as improved job performance, less absenteeism, and better organizational efficiency and productivity (Podsakoff et al., 2009). Personality traits such as conscientiousness and other-oriented empathy predict OCB (Borman et al., 2001).

Counterproductive work behavior (CWB) describes behavior harming or intending to harm an organization or its members. It relates to co-workers and supervisors (Spector 
\& Fox, 2005) and has extensive negative financial impact (US Chamber of Commerce, 2002). Dark personality traits positively predict such behavior (O'Boyle et al., 2012), whereas traits such as agreeableness and conscientiousness negatively predict CWB (Runge et al., 2020). Transformational leadership negatively predicts employee CWB by reducing conflicts and negative emotions (Kessler et al., 2013).

The dark triad variables usually relate negatively to OCB (Webster \& Smith, 2019) and positively to CWB (O'Boyle et al., 2012). Similarly, dominance should relate negatively to $\mathrm{OCB}$ and positively to CWB because people forcing others to obey should also be less willing to enhance the organizational environment themselves and show more harmful behavior toward their co-workers. In contrast, prestige should positively relate to OCB but negatively to CWB because engaging in extra-role behavior should increase one's prestige, whereas engaging in antisocial behavior should make people less admired and respected in the organization. The same should be true for leadership because people who take responsibility for their group should show more extra-role and less harmful behavior at work.

Therefore, we posit

Hypothesis 2: Dominance predicts CWB, whereas prestige and leadership predict OCB.

We expect similar effects for leadership styles.

\section{Transformational and Transactional Leadership Styles}

Transformational and transactional leadership have been the most researched leadership styles for the last 30 years. While transactional leadership focuses on exchanging resources, transformational leadership goes beyond shortterm goals, focusing instead on the purpose of organizational action. Charisma, vision, identification, and inspiration, are also included in transformational leadership (Lord et al., 2017). Transactional leadership styles include Contingent Rewards, Active and Passive Management by Exceptions, and sometimes Laissez-faire. They are more passive and less effective than transformational leadership styles, as the latter entails active involvement of the leader through Idealized Influence, Inspirational Motivation, Intellectual Stimulation, and Individualized Consideration. They relate more strongly to positive outcomes than transactional leadership styles (Judge et al., 2006). Meta-analytic evidence suggests that transformational leadership positively affects followers' satisfaction with the leader, motivation, and perceived leader effectiveness (Judge \& Piccolo, 2004) but also, among many others, OCB and job performance (Hoch et al., 2018; Nohe \& Hertel, 2017).
A certain desire for power appears to be beneficial in a leadership position since leading others means exerting influence to achieve common goals. However, leaders can influence their subordinates by coercion (dominance), by demonstrating ones' competence so that subordinates will want to follow (prestige), or by assuming the responsibility for leadership and showing one's willingness to guide (leadership). Coercing or rewarding ones' subordinates seems to fit a transformational leadership style less, which is all about inspiring one's followers. In contrast, acting as a competent model at work, inspiring followers, and providing a direction and vision fit transformational leadership styles better. Therefore, we posit

Hypothesis 3: Dominance correlates negatively, whereas prestige and leadership correlate positively with transformational leadership styles.

Since transformational leadership styles positively relate to OCB (Hoch et al., 2018; Nohe \& Hertel, 2017) and negatively to CWB (Kessler et al., 2013), we posit

Hypothesis 4: Transformational leadership mediates the relations between prestige and leadership, respectively, with OCB and CWB.

We tested our hypotheses in two correlational studies. Study 1 used a cross-sectional design with employees. Study 2 used a leader population and a larger sample to also test the mediation hypothesis in a prospective design with three measurement points.

\section{Study 1}

This study explored the nomological network of dominance, prestige, and leadership in relation to narcissism, Machiavellianism, and psychopathy, as well as OCB and CWB. We tested Hypotheses 1a-1c and 2 in a cross-sectional survey study with employees.

\section{Method}

\section{Participants}

We assessed $N=151$ full-time employees, of which 111 passed all the attention checks. They were between 21 and 64 years old $(M=34.01, S D=7.66,57.7 \%$ women $)$ and came from 18 different countries in Europe (84.7\%), North (13.5\%), and South America (0.02\%). 46.8\% came from English-speaking countries. 36.04\% were native English speakers, and the others had learned English between the age of 3 and $25(M=7.00, S D=6.23) .11 .7 \%$ were enrolled as students. Most participants had a university degree (32.4\% graduate, $37.7 \%$ undergraduate). 


\section{Procedures}

We recruited participants through the online platform Prolific (https://www.prolific.co/) to participate in a study on "Social Interaction at Work". Participants received £7.50/ hour for their participation, which included questionnaires measuring the three explicit power motives, the dark triad, CWB, OCB, and demographic questions, as well as other variables that were part of a different project (see Electronic Supplementary Material, ESM 1, A).

\section{Measures}

We measured the three explicit power motives with the DoPL scales using six items per sub-dimension (Suessenbach et al., 2019). We measured the dark triad using The Dirty Dozen Scale. Jonason and Webster (2010) developed this scale to assess the three traits as different measures of the same latent construct, using four items per sub dimension. We measured CWB and OCB using 10 item versions of the CWB and the OCB Checklists, respectively (Spector et al., 2010). These checklists ask participants how often they have done the behavior mentioned in the items (see ESM 1, A for further description). The reliabilities of all measures were acceptable to good (Table 1).

\section{Results}

Machiavellianism, psychopathy, and CWB were positively skewed. Thus, we applied a logarithmic transformation, which improved their normality. Correlations (Table 1) show that dominance positively correlated with all three dark personality traits but the strongest with Machiavellianism. Prestige correlated strongly with narcissism and weakly with Machiavellianism but not with psychopathy. Leadership was only moderately correlated with narcissism. This pattern supports Hypotheses 1a-1c. Regression analysis showed a similar pattern (ESM 1, B, Table E3).

Table 1 also shows that dominance positively correlated with CWB and, unexpectedly, also with OCB. As expected, prestige and leadership correlated positively with OCB but not with CWB. In order to test Hypothesis 2, we conducted two hierarchical regression analyses of dominance, prestige, and leadership predicting OCB and CWB, respectively. We controlled for age, gender, and for living in an Englishspeaking country. We then added narcissism, Machiavellianism, and psychopathy as predictors. This procedure allowed us to evaluate whether the three power motives explained variance over and above the dark triad variables. The results (ESM 1, B, Table E4) show that only leadership significantly predicted OCB even when adding narcissism, Machiavellianism, and psychopathy $(\beta=.44, p<.001)$. In contrast, only dominance predicted CWB $(\beta=.26, p=$ $.01)$, but this effect disappeared when entering the dark triad - now Machiavellianism $(\beta=.28, p=.02)$ significantly predicted CWB. These results only partially support Hypothesis 2.

\section{Brief Discussion}

These results suggest that dominance shares variance with narcissism, Machiavellianism, and psychopathy, yet dominance does not explain variance over and above Machiavellianism in CWB. On the other hand, prestige and leadership appear to share variance essentially with narcissism and predict OCB. While these results provide first insights into the nomological network of dominance, prestige, and leadership with dark personality traits as well as with positive and negative work behavior of employees, the nature of the cross-sectional design does not allow inferring any causality or directionality of the associations. Furthermore, we assume that the power motives are particularly relevant for leadership since power is an inherent component of leading others. Therefore, Study 2 examines the relations of leaders' dominance, prestige, and leadership motives with leadership styles and subsequent work behavior, using a prospective design.

\section{Study 2}

The aim of Study 2 was to replicate the nomological network established in Study 1 with a different population (leaders), a bigger sample, and a prospective design and to investigate the associations with transformational and transactional leadership styles. Finally, we aimed at testing the mediation hypothesis using path analysis.

\section{Method}

\section{Participants}

We assessed participants $(49.7 \%$ women, age $M=40.61$, $S D=11.15)$ three times over three months $(17.2 \%$ attrition rate). The initial sample $(N=371)$ was reduced to $N=$ 361 once participants who failed attention checks were excluded. Participants were English-speaking jobholders with leadership responsibilities ( $\geq 3$ subordinates), who had not participated in Study 1. Most reported positions such as manager, supervisor, or team leader (54.8\%). Others were nurses, engineers, or professors/researchers (16\%). Most participants came from the UK $(57.9 \%)$ or the US (19.7\%). English was the majority's mother tongue (77.6\%).

\section{Procedure and Measures}

The procedure resembled Study 1 with the difference that we measured the power motives at $\mathrm{T} 1$, leadership at $\mathrm{T} 2$, 
Table 1. Means (M), standard deviations (SD), and inter-correlations of the variables in Studies 1 and 2

\begin{tabular}{|c|c|c|c|c|c|c|c|c|c|c|c|c|c|}
\hline Study 1 & M & $S D$ & 1 & 2 & 3 & 4 & 5 & 6 & 7 & 8 & 9 & & \\
\hline 1. Dominance & 2.58 & 0.86 & .85 & $.24^{\star}$ & $.22 \star \star$ & $.45^{\star \star \star}$ & $.56 * \star \star$ & $.46^{\star \star \star}$ & $.21 *$ & $.26 * \star$ & -.05 & & \\
\hline 2. Prestige & 4.34 & 0.74 & & .80 & $.30 * *$ & $.53^{* * *}$ & $.22^{\star}$ & .05 & $.33 * *$ & -.01 & -.12 & & \\
\hline 3. Leadership & 3.71 & 0.99 & & & .91 & $.30 \star \star$ & .15 & .07 & $.49 * * *$ & .05 & -.08 & & \\
\hline 4. Narcissism & 2.49 & 0.88 & & & & .83 & $.59 * \star \star$ & $.40 * \star \star$ & $.21 *$ & $.28 * \star$ & $-.23 *$ & & \\
\hline 5. Machiavellianism & 1.85 & 0.67 & & & & & .73 & $.50 \star \star \star$ & .13 & 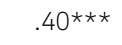 & -.11 & & \\
\hline 6. Psychopathy & 1.90 & 0.74 & & & & & & .69 & -.01 & $.38 * * *$ & .01 & & \\
\hline 7. OCB & 2.96 & 0.70 & & & & & & & .85 & .09 & -.03 & & \\
\hline 8. $\mathrm{CWB}$ & 1.71 & 0.42 & & & & & & & & .65 & .13 & & \\
\hline 9. Age & 34.01 & 7.67 & & & & & & & & & - & & \\
\hline Study 2 & M & $S D$ & 1 & 2 & 3 & 4 & 5 & 6 & 7 & 8 & 9 & 10 & 11 \\
\hline 1. T1 Dominance & 2.65 & 0.97 & .86 & $.40 * * \star$ & $.19 * \star \star$ & $.42^{\star * \star}$ & 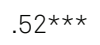 & $.42 * \star \star$ & -.03 & $.28 * \star *$ & -.09 & $.11 *$ & $-.15^{\star \star}$ \\
\hline 2. T1 Prestige & 3.92 & 0.85 & & .80 & $.43 * \star \star$ & $.56^{* \star *}$ & $.17 * \star \star$ & .05 & $.25^{\star * *}$ & .00 & $.30 * * *$ & $.39 * * *$ & $-.19 * * *$ \\
\hline 3. T1 Leadership & 4.16 & 0.96 & & & .90 & $.28^{* * *}$ & $.10^{\dagger}$ & $-.10^{\dagger}$ & $28^{\star \star *}$ & -.08 & $.47 * \star \star$ & $.37 * * *$ & .05 \\
\hline 4. T3 Narcissism & 2.11 & 0.80 & & & & .81 & $.52^{\star \star \star}$ & $.26 * \star *$ & $.14^{\star \star}$ & $.27 * \star \star$ & $.14^{\star \star}$ & $.25^{\star \star *}$ & $-.16^{* \star}$ \\
\hline 5. T3 Machiavellianism & 1.73 & 0.67 & & & & & .83 & $.61 * \star *$ & .00 & $.52 * \star \star$ & $-.15^{\star \star}$ & -.00 & -.06 \\
\hline 6. T3 Psychopathy & 1.80 & 0.70 & & & & & & .73 & -.08 & $.42 * \star *$ & 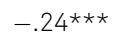 & -.06 & $-.12^{\star}$ \\
\hline 7. ТЗ ОСВ & 3.24 & 0.63 & & & & & & & .83 & .03 & $.49 * * *$ & $.38 * * *$ & $-.10^{\dagger}$ \\
\hline 8. T3 CWB & 1.24 & 0.30 & & & & & & & & .93 & $-.24^{\star \star \star}$ & -.07 & $-.15^{\star \star \star}$ \\
\hline 9. T2 TFL & 3.86 & 0.59 & & & & & & & & & .93 & $.65^{\star \star \star}$ & -.00 \\
\hline 10. T2 TAL & 3.60 & 0.57 & & & & & & & & & & .74 & -.08 \\
\hline 11. T3 age & 40.85 & 11.28 & & & & & & & & & & & - \\
\hline
\end{tabular}

Note. Cronbach's $\alpha$ on the diagonal (Italicized). TFL = Transformational Leadership; TAL = Transactional Leadership; OCB = Organizational Citizenship Behavior; $\mathrm{CWB}=$ Counterproductive Work Behavior. All correlations are two-tailed. ${ }^{\dagger} p<.10 ;{ }^{\star} p<.05 ;{ }^{*} p<.01 ;{ }^{* *} p<.001$.

and the dark triad, OCB, and CWB at T3. We also measured other variables as part of a different project (ESM 1, A). We used the same scales as in Study 1 for the power motives, OCB, and the dark triad but a 32-item version for CWB (Spector et al., 2006) using the total score. We measured transformational and transactional leadership with items from the Multifactor Leadership Questionnaire (Avolio et al., 1999) (see ESM 1, A for further details). The reliability of all variables was acceptable to good (Table 1).

\section{Results}

\section{Preliminary Analyses}

The correlations of dominance, prestige, and leadership with narcissism, Machiavellianism, and psychopathy resemble those of Study 1 but over three months (Table 1). In addition, dominance correlated positively with transactional leadership styles, albeit weakly. Prestige and leadership correlated much stronger and positively with both leadership styles. Interestingly, prestige correlated stronger with transactional than with transformational leadership, while the opposite occurred for leadership. Both leadership styles correlated positively with $\mathrm{OCB}$, while transformational leadership correlated only negatively and weakly with CWB.

We first tested a bifactor model, which confirmed the value of measuring the power motives separately (ESM 1 ,
A). Before specifying our path model, we tested assumptions. Missing data were missing completely at random $(p=.49)$, but assumptions of multivariate normality and linearity between the variables in the path model were violated. Hence, we used a maximum likelihood estimation with bootstrapping (1,000 samples) to address the violation of normality and applied a winsorization procedure, which decreased the linearity problem (Kennedy et al., 1992).

\section{Main Analyses}

We conducted a path analysis using R's lavaan package (Rosseel, 2012) with $\mathrm{T} 1$ dominance, prestige, and leadership predicting $\mathrm{T} 2$ transformational and transactional leadership, in turn, predicting T3 OCB and CWB. We controlled OCB and CWB for narcissism, Machiavellianism, and psychopathy (T3). The model also controlled for the effect of age and gender on every path, except for the one on the covariances. The model included 12 indirect paths (ESM $1, \mathrm{~B}$, Table E5) and had a good fit $(\mathrm{CFI}=.98$, TLI $=.94$, RMSEA $=.05,90 \%$ CI $[.02, .08]$, SRMR $=.02$, AIC $=$ $1,171.95, \mathrm{BIC}=1,288.70$ ), while comparison models (ESM 1, A) had poorer fit or did not add relevant information.

Figure 1 shows that all the power motives significantly predicted transformational leadership. Importantly, the coefficient for dominance was negative, while those for prestige and leadership were positive. Not surprisingly, the 


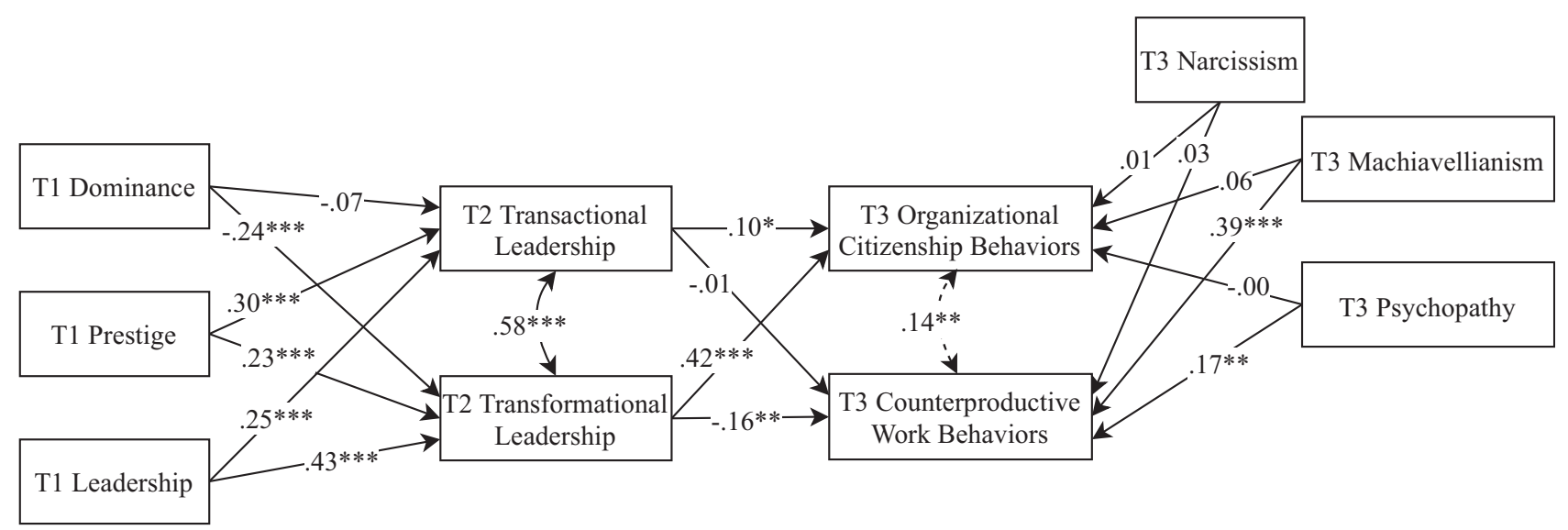

Figure 1. The Final model for Study 2 depicting the standardized path coefficients between T1 explicit power subscales, T2 transformational and transactional styles, and T3 orgranizational citizenship behavior and counterproductive work behavior. This model also took into consideration the impact of dark personality traits (Machiavellianism, narcissism, and psychopathy) on counterproductive work behavior and organizational citizenship behavior. It also controls for age and gender for the whole model (gender and age paths are not shown for clarity sake). ${ }^{*} p<.05 ;{ }^{* \star} p<$ $.01 ; * \star * p<.001$.

relation between leadership and transformational leadership was the strongest among the three power motives. A similar pattern occurred for transactional leadership except that the coefficient for dominance was nonsignificant. This time, the effect size for prestige was larger than the one for leadership. Overall, this pattern supports Hypothesis 3.

Moreover, transformational leadership significantly predicted OCB and CWB, while transactional leadership predicted OCB but not CWB. Mind that we controlled OCB and CWB for the dark triad variables, of which Machiavellianism and psychopathy were associated with CWB, but not OCB. The six indirect effects of the three power motives via transformational leadership on OCB and CWB were significant. In contrast, only two of the indirect effects of transactional leadership were significant (ESM 1, B, Table E5). This supports Hypothesis 4.

\section{Brief Discussion}

Using a prospective design with a population of leaders, Study 2 showed a nomological network of dominance, prestige, and leadership with narcissism, Machiavellianism, psychopathy, OCB, and CWB similar to Study 1 . We also found support for Hypothesis 3, with results showing that dominance relates negatively, while prestige and leadership relate positively to transformational leadership. Finally, we found support for the mediation Hypothesis 4. Overall, the results show that the three power motives have specific correlations with the dark triad variables and predict positive and negative work behavior differently. Therefore, desiring power at work is a double-edged sword and whether it relates to positive or negative work behavior depends on the specific power motives: dominance, prestige, and leadership.

\section{Discussion}

This paper aimed at exploring (1) the extent to which the explicit power motives for dominance, prestige, and leadership related to the dark triad (narcissism, Machiavellianism, and psychopathy), (2) how they relate to positive and negative work behavior, and (3) whether leadership styles can explain these relations. We explored these research questions in one cross-sectional study with $N=151$ employees, using regression analyses, and in one prospective study with $N=371$ leaders, using path analyses. Both studies revealed that dominance is most strongly related to Machiavellianism and moderately to narcissism and psychopathy. Prestige related strongly to narcissism and weakly to Machiavellianism, while leadership only weakly related to narcissism. Not surprisingly, dominance best predicted CWB, yet this relation disappeared when controlling for Machiavellianism and psychopathy. In contrast, leadership best predicted $\mathrm{OCB}$, and this remained unchanged when controlling for the dark triad variables. In addition, Study 2 showed that transformational and, to a lesser extent, transactional leadership styles mediated the relations between the three power motives with $\mathrm{OCB}$ and $\mathrm{CWB}$, respectively, even when controlling for narcissism, Machiavellianism, and psychopathy.

\section{Implications}

The results support the idea that the desire for power can motivate employees as well as leaders to engage in positive and negative work behavior. People high in dominance are more likely to also rate high on all dark triad traits, particularly Machiavellianism, use less transformational leadership styles, and show less OCB but more CWB. People high in 
prestige and, to some extent, in leadership are more likely to score high on narcissism, use more transformational leadership styles and show more OCB but less CWB. Despite some clear similarities, we should not consider the explicit power motives dark personality traits as such. In fact, striving for power has a darker (dominance) and a brighter (leadership) side - but how about prestige? Prestige seems to reflect the double-edged character of wanting power the best: it relates to narcissism and, to some extent, to Machiavellianism, yet it only predicted positive work behavior in our studies. Moreover, it positively predicted transformational and transactional leadership, but the correlation with transactional leadership was stronger. This highlights the need for more research on the prestige motive at work.

Transformational leadership styles can be a good way of feeling strong and impactful and satisfying one's desire for power in a pro-social way. Fortunately, leaders can learn using transformational leadership styles (Lacerenza et al., 2017). In addition, mindfulness interventions might be a means of supporting leadership development because skills such as self-awareness, self-regulation, and self-motivation lie at the heart of any formal leadership role (Furtner et al., 2017). Evidence suggests that mindfulness fosters several intrapersonal skills: self-regulation (Leyland et al., 2019), motivation (Donald et al., 2020), and emotion regulation (Marion-Jetten et al., 2021). Moreover, Decuypere and colleagues (2018) found that mindfulness fosters transformational leadership styles, particularly in leaders with high neuroticism. Taken together, transformational leadership training and mindfulness interventions appear to be a promising way of channeling leaders' desires for power into pro-social power-related actions.

\section{Limitations and Future Research}

While our research investigated the dark triad as omnibus traits (Paulhus \& Williams, 2002), it paid no empirical tribute to the multidimensional nature of narcissism, Machiavellianism, and psychopathy, as outlined in the introduction. It would be interesting to further explore the three power motives' relations with subcomponents of all dark triad variables. Narcissism would be particularly interesting given its many sub-dimensions (Crowe et al., 2019), that it not only has a dark side (e.g., Helfrich \& Dietl, 2019), and given that it seems to interact with having power (Macenczak et al., 2016). We think that approaches mapping dark traits on the five-factor model of personality seem promising, as they maintain the notion of dark traits as personality factors and not as disorders (e.g., Du et al., 2021).

Another limitation of this research was that all the variables were measured using self-reports, leading to method bias. Although we have tried to reduce this issue through temporal separation in Study 2 (Podsakoff et al., 2012), data might still be affected by mono source bias. Often, researchers reduce this bias by collecting peer evaluations. For example, we could have collected subordinates' perceptions on leaders' leadership styles or subordinates' OCB and CWB. Unfortunately, this was not possible through the online platform Prolific. Future research should consider this option.

Finally, we aimed at distinguishing the bright from the dark side of desiring power at work. While the literature describes transformational leadership as the more effective style (Judge \& Piccolo, 2004), one can hardly consider transactional leadership destructive. Therefore, we explored pseudo-transformational leadership (Barling et al., 2008) - the unethical facet of transformational leadership - as a possible more destructive leadership style (ESM 1, A). Pseudo-transformational leadership combines low idealized influence and high inspirational motivation, which shares some similarities with narcissistic leadership (Rosenthal \& Pittinsky, 2006). However, in our regression models, pseudo-transformational leadership did not significantly predict work behavior, nor did narcissism predict pseudo-transformational leadership. Hence, future studies should delve deeper into other destructive leadership styles to better understand the relations between the explicit power motives, the dark triad, and leadership.

\section{Conclusion}

Dominance motivates people with strong dark personality traits, particularly Machiavellians. Prestige motivates particularly narcissists, while leadership seems to motivate dark personalities the least - if it does, it is mostly narcissists. Transformational leadership might be a fruitful way of channeling the explicit power motives at work into pro-social action.

\section{Electronic Supplementary Material}

The electronic supplementary material is available with the online version of the article at https://doi.org/ 10.1027/2151-2604/a000481

ESM 1. Supplementary analyses with parts A and B (including Tables E3: Regression analysis; E4: Hierarchical regression analyses of dominance, prestige, and leadership predicting OCB and CWB respectively; and E5: Indirect paths of Study 2).

\section{References}

Ackerman, R. A., Witt, E. A., Donnellan, M. B., Trzesniewski, K. H., Robins, R. W., \& Kashy, D. A. (2011). What does the narcissistic personality inventory really measure? Assessment, 18(1), 6787. https://doi.org/10.1177/1073191110382845 
Avolio, B. J., Bass, B. M., \& Jung, D. I. (1999). Re-examining the components of transformational and transactional leadership using the Multifactor Leadership. Journal of Occupational and Organizational Psychology, 72(4), 441-462. https://doi.org/ 10.1348/096317999166789

Back, M. D., Küfner, A. C. P., Dufner, M., Gerlach, T. M., Rauthmann, J. F., \& Denissen, J. J. A. (2013). Narcissistic admiration and rivalry: Disentangling the bright and dark sides of narcissism. Journal of Personality and Social Psychology, 105(6), 1013-1037. https://doi.org/10.1037/a0034431

Barling, J., Christie, A., \& Turner, N. (2008). Pseudo-transformational leadership: Towards the development and test of a model. Journal of Business Ethics, 81(4), 851-861. https://doi. org/10.1007/s10551-007-9552-8

Borman, W. C., Penner, L. A., Allen, T. D., \& Motowidlo, S. J. (2001). Personality predictors of citizenship performance. International Journal of Selection \& Assessment, 9(1/2), 52-69.

Christie, R., \& Geis, F. L. (1970). Studies in Machiavellianism. Academic Press.

Crowe, M. L., Lynam, D. R., Campbell, W. K., \& Miller, J. D. (2019). Exploring the structure of narcissism: Toward an integrated solution. Journal of Personality, 87(6), 1151-1169. https://doi. org/10.1111/jopy. 12464

Decuypere, A., Audenaert, M., \& Decramer, A. (2018). When mindfulness interacts with neuroticism to enhance transformational leadership: The role of psychological need satisfaction. Frontiers in Psychology, 9, Article 2588. https://doi.org/ 10.3389/fpsyg.2018.02588

Donald, J. N., Bradshaw, E. L., Ryan, R. M., Basarkod, G., Ciarrochi, J., Duineveld, J. J., Guo, J., \& Sahdra, B. K. (2020). Mindfulness and its association with varied types of motivation: A systematic review and meta-analysis using self-determination theory. Personality \& Social Psychology Bulletin, 46(7), 1121-1138. https://doi.org/10.1177/0146167219896136

Du, T. V., Collison, K. L., Vize, C., Miller, J. D., \& Lynam, D. R. (2021). Development and validation of the super-short form of the Five Factor Machiavellianism Inventory (FFMI-SSF). Journal of Personality Assessment, 103(6), 1-17. https://doi.org/ 10.1080/00223891.2021.1878525

Erkoreka, L., \& Navarro, B. (2017). Vulnerable narcissism is associated with severity of depressive symptoms in dysthymic patients. Psychiatry Research, 257, 265-269. https://doi.org/ 10.1016/j.psychres.2017.07.061

Foster, J. D., McCain, J. L., Hibberts, M. F., Brunell, A. B., \& Burke Johnson, R. (2015). The Grandiose Narcissism Scale: A global and facet-level measure of grandiose narcissism. Personality \& Individual Differences, 73, 12-16. https://doi.org/10.1016/ j.paid.2014.08.042

French, J. R. P. Jr, \& Raven, B. (1959). The bases of social power. In D. Cartwright (Ed.), Studies in social power (pp. 150-167). Univer. Michigan.

Furtner, M. R., Maran, T., \& Rauthmann, J. F. (2017). Dark leadership: The role of leaders' dark triad personality traits. In M. G. Clark \& C. W. Gruber (Eds.), Leader development deconstructed (pp. 75-99). Springer.

Helfrich, H., \& Dietl, E. (2019). Is employee narcissism always toxic? - The role of narcissistic admiration, rivalry and leaders' implicit followership theories for employee voice. European Journal of Work \& Organizational Psychology, 28(2), 259-271. https://doi.org/10.1080/1359432X.2019.1575365

Hoch, J. E., Bommer, W. H., Dulebohn, J. H., \& Wu, D. (2018). Do ethical, authentic, and servant leadership explain variance above and beyond transformational leadership? A metaanalysis. Journal of Management, 44(2), 501-529. https://doi. org/10.1177/0149206316665461
Jackson, D. N. (1967). Personality Research Form. Research Psychologists Press.

Jonason, P. K., \& Ferrell, J. D. (2016). Looking under the hood: The psychogenic motivational foundations of the Dark Triad. Personality \& Individual Differences, 94, 324-331. https://doi.org/ 10.1016/j.paid.2016.01.039

Jonason, P. K., \& Webster, G. D. (2010). The dirty dozen: A concise measure of the Dark Triad. Psychological Assessment, 22(2), 420-432. https://doi.org/10.1037/a0019265

Jones, D. N., \& Paulhus, D. L. (2011). Differentiating the dark triad within the interpersonal circumplex. In L. M. Horowitz \& S. Strack (Eds.), Handbook of interpersonal psychology: Theory, research, assessment, and therapeutic interventions (pp. 249267). Wiley. https://doi.org/10.1002/9781118001868.ch15

Judge, T. A., Fluegge Woolf, E., Hurst, C., \& Livingston, B. (2006). Charismatic and transformational leadership. Zeitschrift für Arbeits- und Organisationspsychologie, 50(4), 203-214. https:// doi.org/10.1026/0932-4089.50.4.203

Judge, T. A., \& Piccolo, R. F. (2004). Transformational and transactional leadership: A meta-analytic test of their relative validity. Journal of Applied Psychology, 89(5), 755-768. https://doi.org/10.1037/0021-9010.89.5.755

Kennedy, D., Lakonishok, J., \& Shaw, W. H. (1992). Accommodating outliers and nonlinearity in decision models. Journal of Accounting, Auditing \& Finance, 7(2), 161-190. https://doi.org/ 10.1177/0148558X9200700205

Kessler, S. R., Bruursema, K., Rodopman, B., \& Spector, P. E. (2013). Leadership, interpersonal conflict, and counterproductive work behavior: An examination of the stressor-strain process. Negotiation and Conflict Management Research, 6(3), 180-190. https://doi.org/10.1111/ncmr.12009

Lacerenza, C. N., Reyes, D. L., Marlow, S. L., Joseph, D. L., \& Salas, E. (2017). Leadership training design, delivery, and implementation: A meta-analysis. The Journal of Applied Psychology, 102(12), 1686-1718. https://doi.org/10.1037/apl0000241

LeBreton, J. M., Shiverdecker, L. K., \& Grimaldi, E. M. (2018). The dark triad and workplace behavior. Annual Review of Organizational Psychology and Organizational Behavior, 5(1), 387-414. https://doi.org/10.1146/annurev-orgpsych-032117-104451

Leyland, A., Rowse, G., \& Emerson, L.-M. (2019). Experimental effects of mindfulness inductions on self-regulation: Systematic review and meta-analysis. Emotion, 19(1), 108-122. https://doi.org/10.1037/emo0000425

Lord, R. G., Day, D. V., Zaccaro, S. J., Avolio, B. J., \& Eagly, A. H. (2017). Leadership in applied psychology: Three waves of theory and research. Journal of Applied Psychology, 102(3), 434-451. https://doi.org/10.1037/apl0000089

Lord, R. G., de Vader, C. L., \& Alliger, G. M. (1986). A meta-analysis of the relation between personality traits and leadership perceptions: An application of validity generalization procedures. The Journal of Applied Psychology, 71(3), 402-410. https://doi.org/10.1037/0021-9010.71.3.402

Macenczak, L. A., Campbell, S., Henley, A. B., \& Campbell, W. K. (2016). Direct and interactive effects of narcissism and power on overconfidence. Personality and Individual Differences, 91, 113-122. https://doi.org/10.1016/j.paid.2015.11.053

Marion-Jetten, A. S., Taylor, G., \& Schattke, K. (2021). Mind your goals, mind your emotions: Mechanisms explaining the relation between dispositional mindfulness and action crises. Personality \& Social Psychology Bulletin. Advance online publication. https://doi.org/10.1177/0146167220986310

McClelland, D. C. (1975). Power: The inner experience. Irvington.

McClelland, D. C., \& Boyatzis, R. E. (1982). Leadership motive pattern and long-term success in management. Journal of Applied Psychology, 67(6), 737-743. https://doi.org/10.1037/0021-9010.67.6.737 
McClelland, D. C., Koestner, R., \& Weinberger, J. (1989). How do selfattributed and implicit motives differ? Psychological Review, 96 (4), 690-702. https://doi.org/10.1037/0033-295X.96.4.690

Nohe, C., \& Hertel, G. (2017). Transformational leadership and organizational citizenship behavior: A meta-analytic test of underlying mechanisms. Frontiers in Psychology, 8, Article 1364. https://doi.org/10.3389/fpsyg.2017.01364

O'Boyle, E. H., Forsyth, D. R., Banks, G. C., \& McDaniel, M. A. (2012). A meta-analysis of the Dark Triad and work behavior: A social exchange perspective. Journal of Applied Psychology, 97 (3), 557-579. https://doi.org/10.1037/a0025679

Organ, D. W. (1997). Organizational citizenship behavior: It's construct clean-up time. Human Performance, 10(2), 85-97. https://doi.org/10.1207/s15327043hup1002_2

Patrick, C. J., Fowles, D. C., \& Krueger, R. F. (2009). Triarchic conceptualization of psychopathy: Developmental origins of disinhibition, boldness, and meanness. Development and Psychopathology, 21(3), 913-938. https://doi.org/10.1017/ S0954579409000492

Paulhus, D. L., \& Williams, K. M. (2002). The Dark Triad of personality: Narcissism, Machiavellianism, and psychopathy. Journal of Research in Personality, 36(6), 556-563. https://doi. org/10.1016/S0092-6566(02)00505-6

Podsakoff, N. P., Whiting, S. W., Podsakoff, P. M., \& Blume, B. D. (2009). Individual- and organizational-level consequences of organizational citizenship behaviors: A meta-analysis. The Journal of Applied Psychology, 94(1), 122-141. https://doi.org/ 10.1037/a0013079

Podsakoff, P. M., MacKenzie, S. B., \& Podsakoff, N. P. (2012). Sources of method bias in social science research and recommendations on how to control it. Annual Review of Psychology, 63, 539-569. https://doi.org/10.1146/annurevpsych-120710-100452

Pöhlmann, K., \& Brunstein, J. C. (1997). GOALS: Ein Fragebogen zur Messung von Lebenszielen [GOALS: A questionnaire for assessing life goals]. Diagnostica, 43(1), 63-79.

Pratto, F., Sidanius, J., Stallworth, L. M., \& Malle, B. F. (1994). Social dominance orientation: A personality variable predicting social and political attitudes. Journal of Personality and Social Psychology, 67(4), 741-763. https://doi.org/10.1037/00223514.67.4.741

Raskin, R. N., \& Hall, C. S. (1979). A Narcissistic Personality Inventory. Psychological Reports, 45(2), Article 590. https://doi. org/10.2466/pr0.1979.45.2.590

Rosenthal, S. A., \& Pittinsky, T. L. (2006). Narcissistic leadership. The Leadership Quarterly Yearly Review of Leadership, 17(6), 617-633. https://doi.org/10.1016/j.leaqua.2006.10.005

Rosseel, Y. (2012). Lavaan: An R package for structural equation modeling. Journal of Statistical Software, 48(2), 1-36. https:// doi.org/10.18637/jss.v048.i02

Runge, J. M., Lang, J. W., Zettler, I., \& Lievens, F. (2020). Predicting counterproductive work behavior: Do implicit motives have incremental validity beyond explicit traits? Journal of Research in Personality, 89, Article 104019. https://doi. org/10.1016/j.jrp.2020.104019

Schönbrodt, F. D., \& Gerstenberg, F. X. R. (2012). An IRT analysis of motive questionnaires: The Unified Motive Scales. Journal of Research in Personality, 46(6), 725-742. https://doi.org/ 10.1016/j.jrp.2012.08.010

Schwartz, S. H. (1994). Beyond individualism/collectivism: New cultural dimensions of values. In U. Kim, H. C. Triandis, C. Kâğitçibași, S.-C. Choi, \& G. Yoon (Eds.), Cross-cultural research and methodology series: Vol. 18. Individualism and collectivism: Theory, method, and applications (pp. 85-119) Sage Publications.

Schyns, B., \& Schilling, J. (2013). How bad are the effects of bad leaders? A meta-analysis of destructive leadership and its outcomes. The Leadership Quarterly, 24(1), 138-158. https:// doi.org/10.1016/j.leaqua.2012.09.001

Spector, P. E., Bauer, J. A., \& Fox, S. (2010). Measurement artifacts in the assessment of counterproductive work behavior and organizational citizenship behavior: Do we know what we think we know? The Journal of Applied Psychology, 95(4), 781790. https://doi.org/10.1037/a0019477

Spector, P. E., \& Fox, S. (2005). The stressor-emotion model of counterproductive work behavior. In S. Fox \& P. E. Spector (Eds.), Counterproductive work behavior: Investigations of actors and targets (1st ed., pp. 151-174). APA. https://doi.org/ 10.1037/10893-007

Spector, P. E., Fox, S., Penney, L. M., Bruursema, K., Goh, A., \& Kessler, S. (2006). The dimensionality of counterproductivity: Are all counterproductive behaviors created equal? Journal of Vocational Behavior, 68(3), 446-460. https://doi.org/10.1016/j. jvb.2005.10.005

Suessenbach, F., Loughnan, S., Schönbrodt, F. D., \& Moore, A. B. (2019). The dominance, prestige, and leadership account of social power motives. European Journal of Personality, 33(1), 7-33. https://doi.org/10.1002/per.2184

US Chamber of Commerce. (2002). Employee benefits study. American International Group.

Webster, B. D., \& Smith, M. B. (2019). The Dark triad and organizational citizenship behaviors: The moderating role of high involvement management climate. Journal of Business and Psychology, 34(5), 621-635. https://doi.org/10.1007/s10869018-9562-9

Winter, D. G. (2006). Taming power. In D. L. Rohde (Ed.), Warren Bennis signatures series. Moral leadership: The theory and practice of power, judgment, and policy (pp. 159-175). Jossey-Bass.

\section{History}

Manuscript received: February 1, 2021

Revision received: June 23, 2021

Accepted: September 10, 2021

Published online December 16, 2021

\section{Acknowledgements}

We thank the Social Sciences and Humanities Research Council of Canada (SSHRC) for their financial support to the first author and the Fonds de Recherche du Québec -Société et Culture (FRQSC) for their financial support to both authors. We also thank Marina Doucerain, Hugues Leduc, and Mathieu Nassif for their statistical advice.

\section{Publication Ethics}

We report how we determined our sample size, all data exclusions (if any), all data inclusion/exclusion criteria, whether inclusion/exclusion criteria were established prior to data analysis, all measures in the study, and all analyses including all tested models. We conducted both studies in accordance with the ethical standards of the American Psychological Association (APA) and the Ethics Committee of Université du Québec à Montréal had approved the research project.

\section{Open Data}

All online supplemental materials and data are publicly accessible at the Open Science Framework (OSF; https://osf.io/w6h4x/).

\section{Kaspar Schattke}

Department of Psychology

Université du Québec à Montréal

CP 8888, Succ. Centre-Ville

Montréal, QC H3C $3 P 8$

Canada

schattke.kaspar_philipp@uqam.ca 